\title{
Hospitalizations and Emergency Department Visits for TBI in Ontario
}

\author{
Angela Colantonio, Cristina Saverino, Brandon Zagorski, Bonnie Swaine, \\ John Lewko, Susan Jaglal, Lee Vernich
}

\begin{abstract}
Objective: The aim of this study was to determine the number of annual hospitalizations and overall episodes of care that involve a traumatic brain injury (TBI) by age and gender in the province of Ontario. To provide a more accurate assessment of the prevalence of TBI, episodes of care included visits to the emergency department (ED), as well as admissions to hospital. Mechanisms of injury for overall episodes were also investigated. Methods: Traumatic brain injury cases from fiscal years 2002/03-2006/07 were identified by means of ICD-10 codes. Data were collected from the National Ambulatory Care Reporting System and the Discharge Abstract Database. Results: The rate of hospitalization was highest for elderly persons over 75 years-of-age. Males generally had higher rates for both hospitalizations and episodes of care than did females. The inclusion of ED visits to hospitalizations had the greatest impact on the rates of TBI in the youngest age groups. Episodes of care for TBI were greatest in youth under the age of 14 and elderly over the age of 85 . Falls (41.6\%) and being struck by or against an object (31.1\%) were the most frequent causes for a TBI. Conclusions: The study provides estimates for TBI from the only Canadian province that has systematically captured ED visits in a national registry. It shows the importance of tracking ED visits, in addition to hospitalizations, to capture the burden of TBI on the health care system. Prevention strategies should include information on ED visits, particularly for those at younger ages.
\end{abstract}

RÉSUMÉ: Hospitalisations et visites à l'urgence pour une lésion cérébrale traumatique en Ontario. Objectif : Le but de cette étude était de déterminer le nombre annuel d'hospitalisations et de demandes de soins en général motivés par une lésion cérébrale traumatique (LCT) selon l'âge et le sexe dans la province d'Ontario. Afin de fournir une évaluation plus exacte de la prévalence des LCT, les visites à l'urgence et les admissions à l'hôpital ont été comptabilisées comme demandes de soins. Les mécanismes du traumatisme pour tous les épisodes ont également été examinés. Méthodologie : Les cas de LCT survenus au cours des années fiscales 2002/03 - 2006/07 ont été identifiés au moyen des codes CIM-10. Les données ont été tirées du Système national d'information sur les soins ambulatoires et de la Base de données sur les congés des patients. Résultats : Le taux d'hospitalisation était plus élevé chez les personnes de plus de 75 ans. Les hommes avaient généralement des taux d'hospitalisations et d'épisodes de soins plus élevés que les femmes. Le fait de comptabiliser les visites à l'urgence avec les hospitalisations avait l'impact le plus grand sur les taux de LCT chez les groupes d'âges inférieurs. Les épisodes de soins pour LCT étaient plus élevés chez les jeunes de moins de 14 ans et chez les gens âgés de plus de 85 ans. Les chutes $(41,6 \%)$ et le fait d'être frappé par ou contre un objet $(31,1 \%)$ étaient les causes les plus fréquentes de LCT. Conclusions : Cette étude fournit des estimés de LCT dans la seule province canadienne qui inscrit a systématiquement les visites à l'urgence dans un registre nationale. Elle montre l'importance de faire le suivi des visites à l'urgence en plus des hospitalisations pour apprécier le fardeau que constitue la LCT sur le système de santé. Les stratégies de prévention devraient mentionner l'information sur les visites à l'urgence, particulièrement chez les jeunes.

Can. J. Neurol. Sci. 2010; 37: 783-790

Traumatic brain injury (TBI) is one of the leading causes of death and disability in North America and as such requires ongoing surveillance ${ }^{1,2}$. Tracking health resource utilization over time, by age, and by gender provides valuable information regarding the burden of TBI on health care services, including post acute care. Furthermore, accurately identifying the rates of TBI is critical to the planning and evaluation of prevention efforts.

Recent reports based on hospital admission data in Canada and the United States have documented a decrease in the number of in-patient admissions over the last two decades ${ }^{3,4}$, particularly for children and for incidents of "mild" TBI (mTBI). Studies that focus on in-patient admissions, however, may be misleading in that the decrease in numbers could reflect a shift towards treating children and mTBI sufferers at emergency departments (EDs). To date, there are no recent peer reviewed studies documenting TBI-related ED visits at a population based level, in a publicly insured population. The lack of research in this area is relevant because US studies have shown that $80-92 \%$ of TBI cases are treated in $\mathrm{EDs}^{5,6}$. In order to obtain accurate estimates of the impact and rates of TBI, ED visits must be included when calculating rates.

From the Acquired Brain Injury Research (AC), Department of Occupational Therapy (CS), Department of Physical Therapy (SJ), Toronto, Rehabilitation Institute; Dalla Lana School of Public Health, Research Services (LV), University of Toronto; Department of Programming and Biostatistics (BZ), Institute for Clinical Evaluative Sciences, Toronto; Centre for Research in Human Development (JL), Laurentian University, Sudbury, Ontario; Physiotherapy Program, School of Rehabilitation (BS), Université de Montréal, Montréal, Quebec, Canada.

Received March 25, 2010. Final Revisions Submitted June 22, 2010. Correspondence to: Angela Colantonio, Saunderson Family Chair in Acquired Brain Injury Research, Toronto Rehabilitation Institute, University of Toronto, 160-500 University Ave., Room 950, Toronto, Ontario, M5G 1V7, Canada. 
Despite "mild" TBI's designation, patients often exhibit physical, cognitive, and behavioural sequelae. Although patients with mTBI can recover within the first few months after injury $^{7-9}$, many report persistent symptoms up to one year post TBI or longer ${ }^{10-14}$. Understanding the mechanisms of injury that include more mild cases may further inform injury prevention efforts.

To our knowledge, only two published Canadian studies have examined the rate of head injuries treated within EDs ${ }^{15,16}$. The study by Pickett and colleagues ${ }^{15}$ reported rates in terms of the causes of external injury; however, only patients from a small, geographically distinct population in Ontario were included. Alternatively, a report by the Canadian Institute for Health Information ${ }^{16}$ examined head injuries across Canada, but did not provide information regarding the causes of injury or detailed information about rates.

The objective of the current study was to provide data on the rates of TBI hospitalizations and overall episodes of care that include ED visits, over a five-year period beginning in 2002, across age and gender, from a Canadian population based perspective. The mechanisms of injury for TBI episodes of care were also reported. Ontario is the only province in Canada that systematically reported ED visits for all residents to a national database during this time period. These results will help identify the burden of TBI on health care services by identifying the contribution of ED visits to TBI rates, which are often based solely on hospital admissions.

\section{METHODS}

\section{Data Sources}

Ontario is located in central Canada and is the most populous province representing 38\% of the Canadian population, or 13 million inhabitants. Ontario has a universal publicly funded health care system. Ontario administrative hospital data are sets of individual records that are routinely collected for the purposes of payment and funding, and are mandated by the Ministry of Health and Long-Term Care. The administrative healthcare databases in Ontario allowed for selection of cases. Hospitalization records were obtained from the Canadian Institute for Heath Information Discharge Abstract Database (DAD), which contains a detailed record of all acute care hospital admissions from over 200 publicly funded hospitals in Ontario since $1963^{17}$. Each record in the dataset contains a patient's health card number, age, gender, postal code, date of admission, date of discharge, most responsible diagnostic codes, as well as secondary and tertiary diagnostic codes based on ICD10 codes. Several chart re-abstraction studies have been performed on these datasets ${ }^{18,19}$. For example, a chart reabstraction study based on data from 1999 through 2002 indicated good agreement $(75 \%$ exact agreement, kappa $=0.78)$ between DAD and chart coding of intracranial injury (S06) ${ }^{18}$.

Data were also obtained from the National Ambulatory Care Resource System (NACRS) database. This database collects information on the reasons (up to ten) for all visits to emergency departments in Ontario, of which there are about 10 million per year across 190 institutions. A recent re-abstraction study of NACRS data compared with 7500 charts from 15 hospitals in 2004-05 found good agreement $(95.3 \%$ at the block level, e.g. S00-S09) in injury between NACRS and chart coding ${ }^{20}$.
Discharge Abstract Database and NACRS are separate databases that are linked using a patient's unique and confidential health card number.

\section{Cases}

All ED visits and hospitalizations between April 1, 2002 and March 31, 2007 that were assigned a TBI code were identified. The following ICD-10 codes were used to capture TBI cases: a fracture of the skull and facial bones $[\mathrm{S} 02(.0, .1, .3, .7, .8, .9)]$, injury to the optic nerve and pathways (S04.0), intracranial injury (S06.0-S06.9), crushing injury of the head (S07.0-S07.9), fractures involving head with neck (T02.0), and sequelae of injuries of the head [T90 (.1-.9)]. The Centers for Disease Control (CDC), and other prior studies, also included other and unspecified injuries of the head (S09.7-S09.9) and open wound to the head (S01.0-S01.9) in their operational case definition of $\mathrm{TBI}^{5,21,22}$ for mortality surveillance since a TBI is likely coincident with a mortal head injury. We did not include these codes because we wanted a more conservative definition of TBI to capture morbidity. On the other hand, sequelae of injuries to the head were used to capture injuries that may not have been seen in acute care/hospitalization. We included codes encompassing mild, moderate and severe levels of TBI severity. In the DAD we used two inclusion criteria for TBI diagnoses: 1) presented at the time of admission, and 2) determined to contribute to the length of stay (i.e. excluding post-admit diagnosis and secondary diagnoses). In NACRS we used the main diagnosis and up to two additional secondary diagnosis fields.

\section{Variables}

Mechanisms of injury were based on the CDC's International Collaborative Effort on Injury Statistics and collapsed into the following categories: motor vehicle collisions, falls, struck by or against an object, and other (e.g. assault (W50, Y00, Y04), self harm, etc. $)^{23}$. Further information was provided to determine which cases were unintentional versus intentional. The number of sports-related injuries (W210 [.0-.1, .3, .8-.9], W220 [.0-.5, .7], W510 [.0-.5, .7]) was also highlighted.

\section{Statistical Analyses}

Two measures of TBI utilization were calculated: acute care admissions and episodes of care. Acute care admissions were determined using the DAD and represented only those admitted to hospital, whether or not they visited the ED. On the other hand, TBI episodes of care included ED visits not admitted, ED visits with admissions, or admissions whereby a TBI code was not captured during an ED visit. It is quite possible that many patients admitted to hospital did not receive a TBI diagnosis when they entered the ED. For TBI episodes of care, a scrambled health card number was used to link acute admissions (DAD) to ED data (NACRS) to ensure that each episode was counted only once. Transfers from ED visits in one hospital to acute care admissions in another hospital were excluded from analyses.

For each measure, we calculated crude annual rates by fiscal year and age group $(0-14,15-24,25-34,35-44,45-54,55-64$, $65-74,75-84,85$ years and older) using fiscal year-specific provincial population estimates for denominators ${ }^{24}$. A fiscal year 


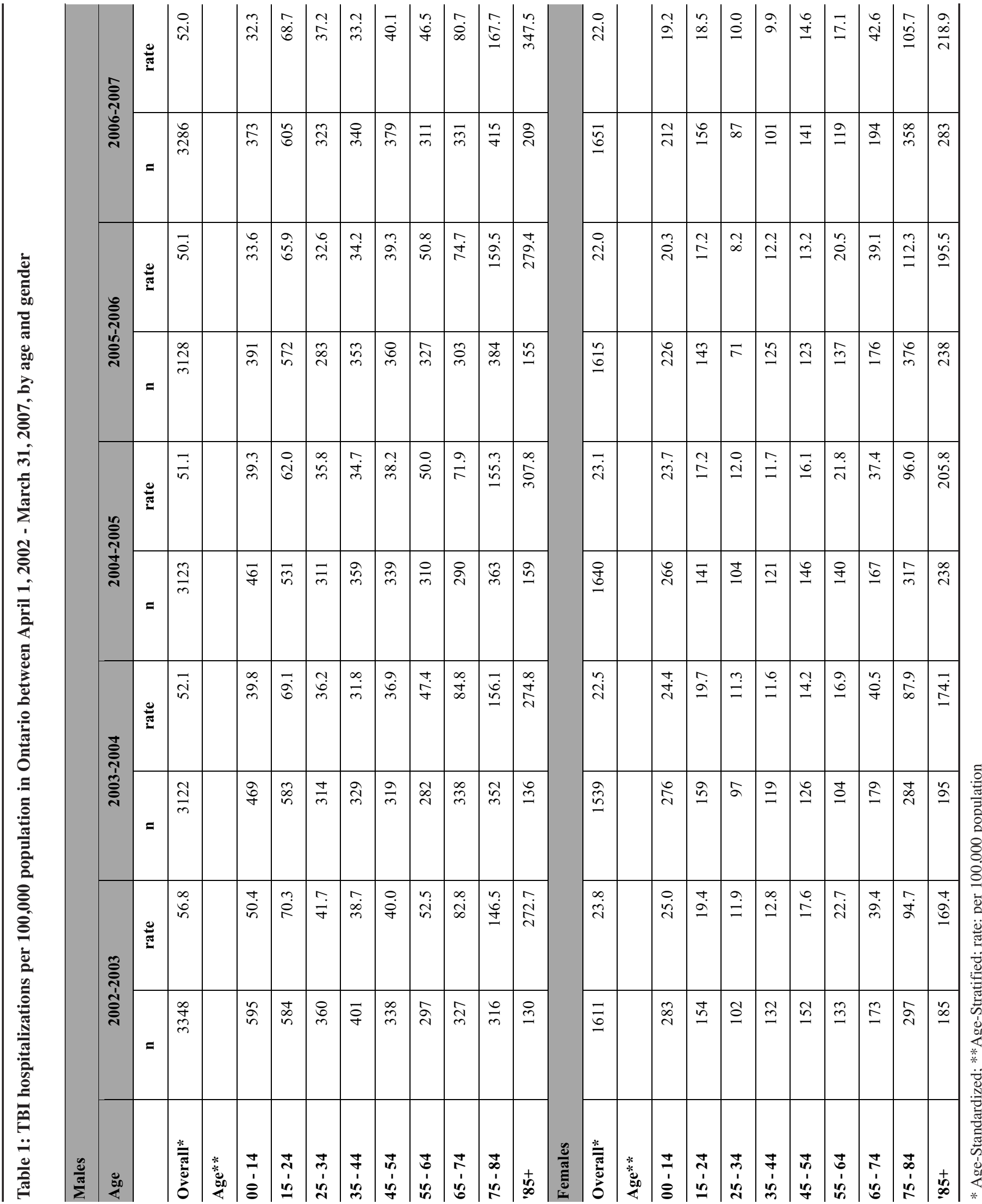




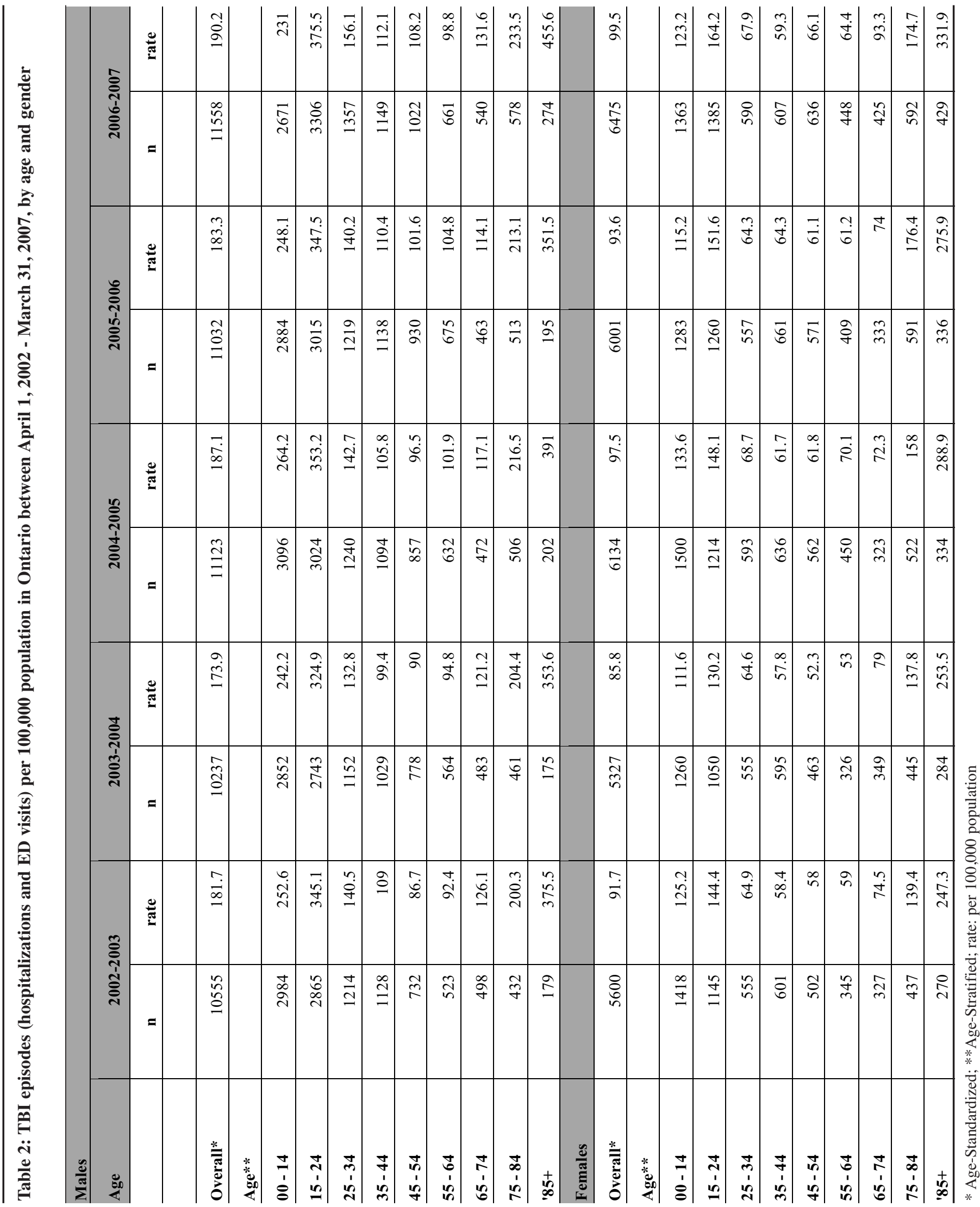


encompassed TBIs that occurred from April 1st of the year investigated to March 31st of the following year. For example, the year 2002-2003 represents data from April 1, 2002 to March 31,2003 . We subsequently generated direct age-standardized rates for the overall study population using the 1991 Canadian population. Mechanisms of injury were based on analyses of episode-level data. A Chi-square test was performed to evaluate significant differences in mechanism of injury by gender.

\section{Results}

Table 1 demonstrates TBI rates per 100,000 of the population by age and gender for hospitalizations, while Table 2 shows TBI rates for episodes of care. The TBI rates fluctuated over time and consequently the results section will mainly focus on differences in rates between age and gender.

\section{Hospitalizations}

Males had a higher rate of TBI hospitalizations than females for all age groups investigated (Table 1). In general, younger males $(<24$ years $)$ had the highest number of TBI hospitalizations but older adults ( $>75$ years) had the highest rates of TBI hospitalization. Older males (+85 years) had rates over 272.7 per 100,000 whereas older females had rates over 169.4 per 100,000 of the population; young males (15-24 years) had rates below 70.3 per 100,000 , and young females had rates below 19.7 per 100,000 . Male and female children under the age of 15 showed declining rates of hospitalization over the five-year time period. The lowest number and rates of hospitalization were in the middle age groups.

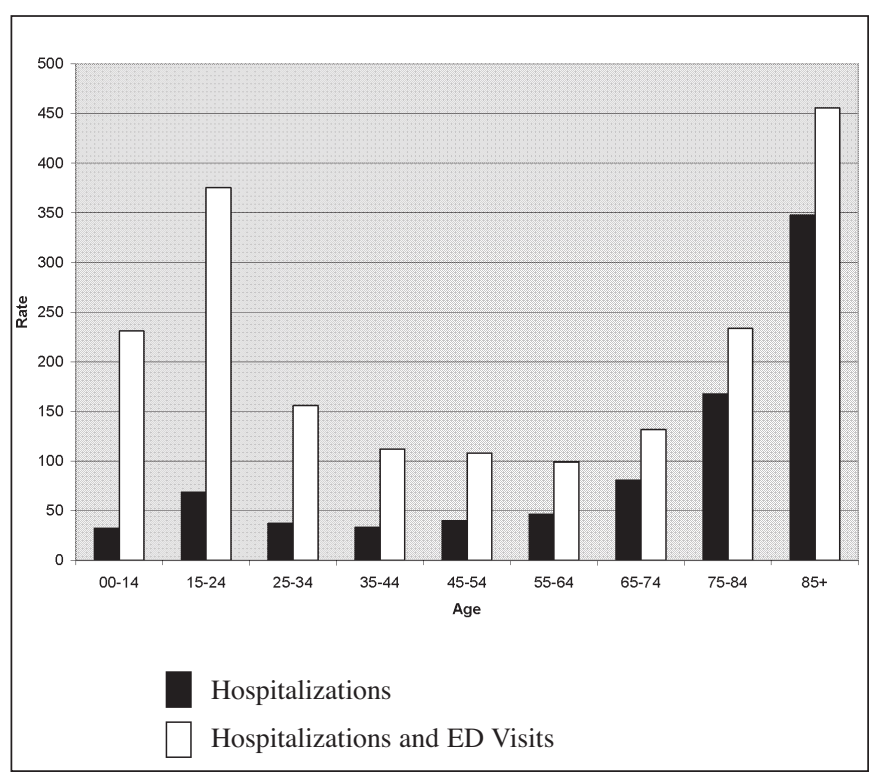

Figure 1: TBI rates of hospitalizations and episodes of care (hospitalizations and ED visits) per 100,000 population in Ontario between April 1st, 2006 - March 31st, 2007, by age for males.

\section{Episodes of Care}

The rates of TBI increased exponentially with the addition of ED visits (Table 2). The greatest impact of including ED visits to hospitalization rates was seen in the youngest age groups $(<24-$ years-old). For instance, the rate of hospitalization of females 15 to 24 -years-old was 18.5 per 100,000 in $2006 / 07$, and the rate of TBI episodes of care for the same group was 164.2 per 100,000 that year. The increase in rates, however, was less apparent for older persons. Similar to hospitalizations, children and young adults represented the greatest number of TBI episodes. In terms of rates, elderly persons over 75-years-old and persons under 24years-old made up the highest rates of TBI. Once again, the lowest rates of TBI were in the middle age groups.

Figures 1 and 2 illustrate the difference between rates of TBI from hospitalizations only and from hospitalizations and ED visits combined, among males and females respectively.

\section{Mechanism of Injury}

Table 3 shows overall mechanisms of injury for TBI episodes by gender. The last two items in the table document other classifications of the types of injury. Falls (41.6\%), struck by and against $(31.1 \%)$ and motor vehicle collisions (11.9\%) were the most commonly reported mechanisms of TBI. Significant differences were observed between mechanism of injury and gender $\left(\chi^{2}(5, N=77414)=2550.12, p<.0001\right)$. A greater number of females than males had a TBI due to a fall. Males had a larger number of TBIs caused by being struck by/against an object. In our other category, two large groups included pedal cycling not involving motor vehicles $(n=2962,3.5 \%)$ and other land transport vehicles $(n=3210,3.8 \%)$. Males and females had roughly equal numbers of TBI due to motor vehicle collisions. A very small number of injuries were due to firearms.

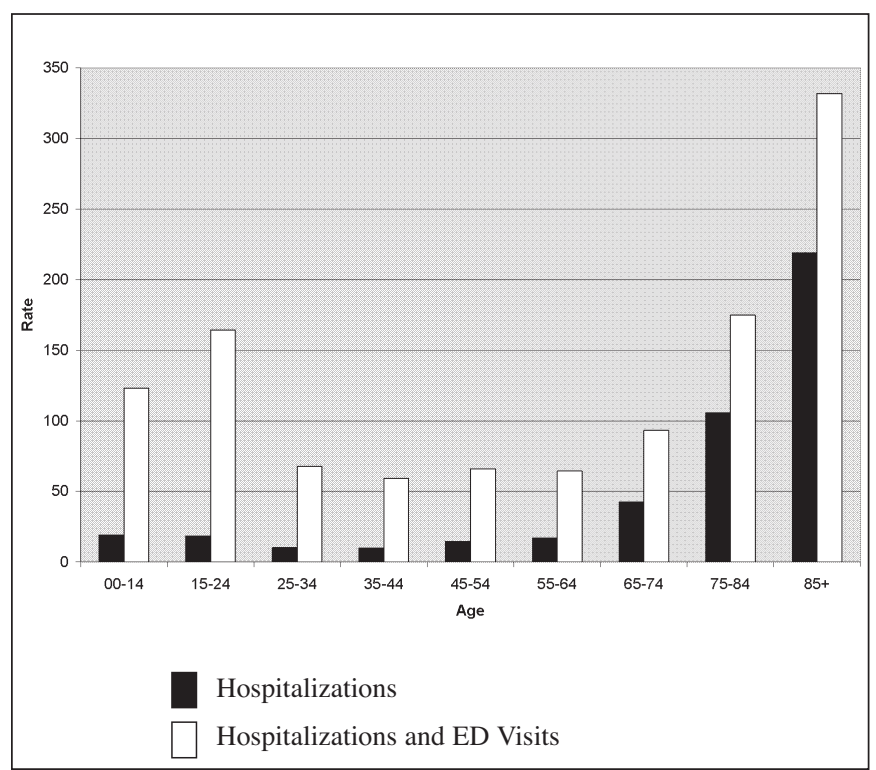

Figure 2: TBI rates hospitalizations and episodes of care (hospitalizations and ED visits) per 100,000 population in Ontario between April 1st, 2006 - March 31st, 2007, by age for females. 
Table 3: Main mechanisms of injury (episodes only) by gender

\begin{tabular}{l|c|c|c|c|c|c}
\hline Mechanism of injury & \multicolumn{2}{|c|}{ Female $\mathbf{n = 2 9 , 5 3 7}$} & \multicolumn{2}{c|}{ Male $\mathbf{n = 5 4 , 5 0 5}$} & \multicolumn{2}{c}{ All } \\
\hline Falls & $\mathbf{n}$ & $\mathbf{\%}$ & $\mathbf{n}$ & $\mathbf{\%}$ & $\mathbf{n}$ & $\mathbf{\%}$ \\
\hline Struck by/ Against & 15,265 & 51.7 & 19,717 & 36.2 & 34,982 & 41.6 \\
\hline Motor vehicle & 6,564 & 22.2 & 19,569 & 35.9 & 26,133 & 31.1 \\
\hline Firearm & 3,882 & 13.1 & 6,081 & 11.2 & 9,963 & 11.9 \\
\hline Other & 16 & 0.1 & 84 & 0.2 & 100 & 0.1 \\
\hline Unintentional & 3,810 & 12.9 & 9,054 & 16.5 & 12,864 & 15.3 \\
\hline Sports Related & 27,956 & 94.6 & 46,876 & 86.0 & 74,832 & 89.0 \\
\hline
\end{tabular}

Unintentional injuries accounted for $89 \%$ of all TBIs. Males had a higher percentage of intentional injuries (14\%) than did females (5.4\%). A notable number of injuries were sports related (20\%) and mainly found in the "struck by" category.

\section{Discussion}

The results of the study demonstrate that the rates of TBI are much greater when taking ED visits into consideration in addition to acute care hospitalizations. The rates were able to provide a more accurate assessment of the burden of TBI on health care services. To our knowledge, this is the first study to provide an overall estimate of annual rates of hospital admissions and episodes of care involving a TBI using ICD-10 codes across age and gender from a publicly insured Canadian population.

The rates of TBI in the present study still remain much lower than previously reported hospitalization and ED rates in Canada $^{2,4}$, the United States ${ }^{25-28}$ and Europe ${ }^{29-31}$. Discrepancies could be the result of differences in the definition of TBI using ICD-10 codes, data source, time period, method of data collection, exclusion criteria with regards to previous head injury, access to health care. Rates may also be lower because of decreases in injuries. This study used a more conservative set of ICD-10 codes than the CDC and earlier reports used ${ }^{5,21,22}$. For instance, when incorporating 'other' and 'unspecified' head injury codes as employed by other studies, the rate of TBI increased to an annual average rate of $623 / 100,000$ between the years 2002-2006. Furthermore, many of the US studies that generated ED rates included visits to outpatient clinics, which would have increased the rate of $\mathrm{TBI}^{26-28}$. Estimates from the US may also be affected by differential access to health care due to varying levels of health insurance coverage in the population.

However, one of the primary purposes of the study was to identify whether the trend of fewer TBI related hospitalizations, as observed in previous reports, was related to a shift in treatment of TBI to EDs rather than hospitalization ${ }^{3,4}$. Based on our findings it appears that many more people are being treated and released with a TBI than are being admitted. This is particularly true of children and adolescents who were shown to have the highest declines in TBI hospitalization in a prior study ${ }^{4}$. This demonstrates the importance of using ED visits to identify the rates and trends of TBI.

Falls have also been documented across multiple studies as a common mechanism of injury for a TBI hospitalization ${ }^{3-5,32,33}$. Children and older persons are especially vulnerable to falls, with older persons being more likely to be hospitalized and children more likely to visit an ED for their injuries ${ }^{5,16,26,27}$. The most common cause of TBI in EDs in the present study was due to falling or being struck by/against an object. The high number of sports related injuries (20\%) in these categories also has implications for prevention. A similar number of medically treated TBIs that resulted from a sports related injury (19\%) were found in an American study ${ }^{34}$. It also may be that persons are more likely to seek care after a sports injury as a result of greater education and public awareness.

Numerous strategies for prevention are needed to reduce the number of TBIs across age and gender categories. Specifically, strategies could be targeted at the major mechanisms of injury, and could address individual behavioural change as well as broader environmental factors, such as legislation and education programs. Canadian government agencies have developed a wide range of media images that promote safety and prevention of injury ${ }^{35}$.

This study was based on administrative data that have known limitations ${ }^{17,36}$. For example, NACRS and DAD databases do not include records of Ontario residents who suffered a TBI outside of the province, who died prior to being taken to an ED or admitted to hospital, or who were treated only in physician offices or in prisons. Another limitation is the possibility that a TBI diagnosis may not be recorded. National Ambulatory Care Resource System, for instance, only codes up to ten diagnoses compared to a hospital, which codes over 20 conditions - and as such a TBI may be missed. 
As stated previously, chart re-abstraction studies demonstrated $75 \%$ agreement between DAD for the coding of intracranial injury ${ }^{18}$, and $95.3 \%$ agreement between NACRS ${ }^{20}$ and chart coding. Lack of agreement may signify underreporting of TBI. In a recently published study by Ryu and colleagues ${ }^{37}$, mTBI rates in persons over the age of 15 were approximately 426 per 100,000 based on hospital data alone but increased to 493 per 100,000 when family physician offices were added. This study demonstrates that more patients are seen for TBIs than are recorded in these administrative databases. Likewise, Kostylova and colleagues found that among children, physician claims underreported head injuries compared to administrative data. That is, instead of reporting a head injury, physicians often documented a head injury as a "multiple unspecified wound or trauma" 38 . Based on these findings and those of another international study ${ }^{39}$ we believe the rates of TBI in our study underestimate the number of actual TBI cases in the population. Further validation studies on diagnosis codes in a Canadian context are needed.

\section{Conclusions}

Our data highlight the importance of emergency room staff training in order to diagnose, treat and make appropriate referrals for TBI. In addition, effective prevention programs - such as providing free bicycle helmets from the ED, and concussion education, including information about return to play-are advocated to avoid re-injury ${ }^{36}$. The higher number of sports related injuries are notable and should be a major focus for prevention and education.

\section{ACKNOWLEDGEMENTS}

The authors thank these institutions for supporting this project: the Ontario Neurotrauma Foundation, the Institute for Clinical and Evaluative Sciences, and the Toronto Rehabilitation Institute. The Institute for Clinical and Evaluative Sciences and the Toronto Rehabilitation Institute are supported by the Ontario Ministry of Health and Long Term Care.

\section{REFERENCES}

1. Greenwald BD, Burnett DM, Miller MA. Brain injury: epidemiology and pathophysiology. Arch Phys Med Rehab. 2003;84(3 Suppl 1):S3-7.

2. Pickett W, Simpson K, Brison JR. Rates and external causes of blunt head trauma in Ontario: analysis and review of Ontario trauma registry datasets. Chronic Dis Can. 2004;25(1):32-41.

3. Thurman D, Guerrero J. Trends in hospitalization associated with traumatic brain injury. JAMA. 1999;282(10):954-7.

4. Colantonio A, Croxford R, Farooq S, Laporte A, Coyote P. Trends in hospitalization associated with traumatic brain injury, 19922002. J Trauma. 2009;66(1):179-83.

5. Rutland-Brown W, Langlois JA, Thomas KE, Lily YL. Incidence of traumatic brain injury in the United States, 2003. J Head Trauma Rehabil. 2006;21(6):544-8.

6. Selassie AW, McCarthy ML, Pickelsimer EE. The influence of insurance, race, and gender on emergency department disposition. Acad Emerg Med. 2003;10(11):1260-70.

7. Belanger HG, Curtiss G, Demery JA, Lebowitz BK, Vanderploeg RD. Factors moderating neuropsychological outcomes following mild traumatic brain injury: a meta-analysis. J Int Neuropsychol Soc. 2005;11(3):215-27.
8. Carroll L, Cassidy JD, Peloso P, et al. Prognosis for mild traumatic brain injury: results of the WHO collaborating centre task force on mild traumatic brain injury. J Rehabil Med. 2004;36 Suppl 43:84-105.

9. McCrea M, Kelly JP, Randolph C, Cisler R, Berger L. Immediate neurocognitive effects of concussion. Neurosurgery. 2002;50(5): $1032-40$

10. Alexander MP. Mild traumatic brain injury - pathophysiology, natural-history, and clinical management. Neurology. 1995;45 (7):1253-60.

11. Cicerone KD, Kalmar, K. Persistent postconcussion syndrome: the structure of subjective complaints after mild traumatic brain injury. J Head Trauma Rehab. 1995;10(3):1-17.

12. Rimel RW, Giordani B, Barth JT, Boll TJ, Jane JA. Disability caused by minor head-injury. Neurosurgery.1981;9(3):221-8.

13. O'Connor C, Colantonio A, Polatajko H. Long term symptoms and activity limitations after traumatic brain injury: a ten year follow-up. Psychol Rep. 2005;97(1):169-79.

14. Vanderploeg RD, Curtiss G, Luis CA, Salazar AM. Long-term morbidities following self-reported mild traumatic brain injury. J Clin Exp Neuropsychol. 2007;29(6):585-98.

15. Pickett W, Ardern C, Brison JR. A population-based study of potential brain injuries requiring emergency care. CMAJ. 2001; $165(3): 288-92$.

16. The burden of neurological diseases, disorders and injuries in Canada: Head injury [Internet]. Ottawa: The Canadian Institute of Heath Information (CIHI); 2007 [cited 2008 Jan 20]. Available from: http://www.icis.ca/cihiweb/dispPage.jsp? cw_page=AR_1689_E.

17. Data quality documentation: discharge abstract database 2002-2003 [Internet]. Ottawa: The Canadian Institute of Heath Information (CIHI); 2007 [cited 2008 Jan 20] Available from: http:// secure.cihi.ca/cihiweb/dispPage.jsp?cw_page=GR_1869_E.

18. Juurlink D, Preyra C, Croxford R, et al. Canadian Institute for Health Information Discharge Abstract Database: a validation study. Toronto (ON): ICES; 2006.

19. Richard J, Brown A, Homan C. The data quality study of the Canadian discharge abstract database. In: Proceedings of Statistics Canada International Symposium Series. Achieving data quality in a statistical agency: a methodological perspective. Ottawa (ON): Statistics Canada; 2001.

20. Data Quality Study of Emergency Department Visits for 20042005: Volume II of IV - Main Study Findings. Ottawa (ON): CIHI; 2008.

21. Marr A, Coronado V. Central nervous system surveillance data submission standards [Internet]. Atlanta: Centre for Disease Control and Prevention, National Center for Injury Prevention and Control; 2002 [cited 2008 March 15]. Available from: http://www.cdc.gov/ncipc/dir/ 2002cnsistrds.pdf.

22. Bazarian JJ, McClung J, Shah MN, Cheng YT, Flesher W, Kraus J. Mild traumatic brain injury in the United States, 1998--2000. Brain Inj. 2005;19(2):85-91.

23. International Collaborative Effort on Injury Statistics. Atlanta: Centre for Disease Control and Prevention, National Center for Injury Prevention and Control; 2007 [cited 2002 December 2]. Available from: http://www.cdc.gov/nchs/injury.htm.

24. Statscan. [cited 2008 Jan 10] Available from: http://wwwstatcan. gc.ca.

25. Day H, Roesler J, Gaichas A, Kinde M. Epidemiology of emergency department-treated traumatic brain injury in Minnesota. Minn Med. 2006;89(5):40-4.

26. Guerrero JL, Thurman DJ, Sniezek JE. Emergency department visits associated with traumatic brain injury: United States, 1995-1996. Brain Inj. 2000;14(2):181-6.

27. Jager TE, Weiss HB, Coben JH, Pepe PE. Traumatic brain injuries evaluated in U.S. emergency departments, 1992-1994. Acad Emerg Med. 2000;7(2):134-40.

28. Schootman M, Fuortes LJ. Ambulatory care for traumatic brain injuries in the US, 1995-1997. Brain Inj. 2000;14(4):373-81.

29. Baldo V, Marcolongo A, Floreani A, et al. Epidemiological aspect of traumatic brain injury in northeast Italy. Eur J Epidemiol. 2003;18(11):1059-63. 
30. Hillier SL, Hiller JE, Metzer J. Epidemiology of traumatic brain injury in South Australia. Brain Inj. 1997;11(9):649-59.

31. Peloso PM, von Holst H, Borg J. Mild traumatic brain injuries presenting to Swedish hospitals in 1987-2000. J Rehabil Med. 2004;36 Suppl 43: 22-7.

32. Jacobsson LJ, Westerberg M, Lexell J. Demographics, injury characteristics and outcome of traumatic brain injuries in northern Sweden. Acta Neuro Scan. 2007;116(5):300-6.

33. Koskinen S, Alaranta H. Traumatic brain injury in Finland 19912005: a nationwide register study of hospitalized and fatal TBI. Brain Inj. 2008;22(3):205-14.

34. Boswell JE, McErlean M, Verdile VP. Prevalence of traumatic brain injury in an ED population. Am J Emerg Med. 2002;20(3): 177-80.

35. Injury prevention [Internet]. Ottawa: Public Health Agency of Canada (PHAC); 2002 [cited 2008 Dec 10]. Available from: http://www.phac-aspc.gc.ca/inj-bles/index-eng.php.
36. Deb S. ICD-10 codes detect only a proportion of all head injury admissions. Brain Inj. 1999;13(5):369-73.

37. Ryu WHA, Feunstein A, Colantonio A, Streiner DL, Dawson D. Early identification and incidence of mild TBI in Ontario. Can J Neurol Sci. 2009;36(4):429-35.

38. Kostylova A, Swaine B, Feldman D. Concordance between childhood injury diagnoses from two sources: an injury surveillance system and a physician billing claims database. Inj Prev. 2005;11(3):186-90.

39. Bazarian JJ, Veazie P, Mookerjee S, Lerner EB. Accuracy of mild traumatic brain injury case ascertainment using ICD-9 codes. Acad Emerg Med. 2006;13(1):31-8. 